hISTOLOGY OF THE HUMAN EYE - An Atlas and Textbook - Michael J. Hogan, MD, Professor and Chairman, Department of Ophthalmology, and Research Associate, Francis I. Proctor Foundation for Research in Ophthalmology; Jorge A. Alvarado, AB, Francis I. Proctor Foundation for Research in Ophthalmology, and Second Year Medical Student; and Joan Espersen Weddell, Medical Illustrator, Department of Ophthalmology, and Francis I. Proctor Foundation for Research in Ophthalmology, all University of Caliornia, San Francisco. W. B. Saunders Company, West Washington Square, Philadelphia, Pa. (19105), 1971. 687 pages, $\$ 34.00$. (A set of $35 \mathrm{~mm}$. teaching slides of drawings and photographs from the book is also available through the publisher.)

This book is divided into twelve chapters, most of which describe in detail the microscopic and ultrastructural anatomy of different parts of the eye. The first chapter is one devoted to a general morphological description of the cell, its membrane, nucleus and cytoplasmic organelles. Although this chapter is not especially oriented toward the central theme of the book, it is a valuable chapter since the reader is introduced to many of the subcellular structures and ultrastructural terms used in the subsequent chapters. The second chapter is short and deals with the general anatomy and topography of the eyeball. From this point on, however the book's chapters become very specialized and discuss sequentially the cornea, limbus, sclera, iris and anterior chamber, ciliary body and posterior chamber, choroid, retina, optic nerve, vitreous and lens. These latter nine chapters are, in fact, excellently presented. They follow an interdisciplinary pattern emphasizing the physiology, biochemistry, embryology, gross anatomy and microscopic anatomy of each of these ophthalmic structures. References are presented at the end of each chapter, and although there are not great numbers of references offered, they are adequate and well selected.

The figures are, perhaps, the finest aspect of this book. Many light and electron micrographs are presented and in most instances they are beautifully done. Additionally, there is a series of excellent three-dimensional drawings which further clarify the text.

This book would be of value not only to professional ophthalmologists, but also to ophthalmic pathologists, to residents in ophthalmology as well as to the research specialists in the visual sciences. It represents a major effort on the part of the authors.

Carmine D. Clemente, PH D

\section{* * * *}

BASIC MEDICAL EDUCATION-David C. Sinclair, MA, MD, DSC, FRCS Ed., Regius Professor of Anatomy, University of Aberdeen, Scotland, Oxford University Press, London (US address of this press: 200 Madison Ave., New York (10016). 1972. 221 pages. 2.40 in UK.

Dr. Sinclair speaks from wide experience, ranging from teaching in the traditional Oxford and Aberdeen universities to personal surveys of American schools and several years in the heart of a new innovational school in Western Australia. The first section of his book deals with the historic backgrounds of teachers, students, and schools. The major section comments on the scope and content of the curriculum, on the acquisition of skills, information, and attitudes, and on assessments and new curricula. A short third section makes pertinent comments in general and suggests a prognosis. Though the angle is British, the overlap with our schools is strong, and the problems are basic even beyond medicine. The balance is noteworthy as Sinclair asks that we hold what we have gained and seek improvement at reasoned speed and in sane ways. The point of view is unbiased and the writing is admirable. A careful index and 11 pages of references, many of them American, both testify to quality and help readers. Though the author steps into confused realms, from teaching to curricula and administration, his adherence to clear sense does much to provoke thought and to clarify academic problems for any student, teacher, administrator, or educator. Sinclair smiles at us over our human failings as he holds us directly to points at issue.

Max S. Marshall, Ph d

$$
\text { * * * }
$$

PEDIATRIC THERAPY-Fourth Edition-Harry C. Shirkey, Editor, BS, MD, Professor and-Chairman, Department of Pediatrics, Tulane University School of Medicine, Senior Visiting Physician and Director, Tulane Pediatric Services, The Charity Hospital of Louisiana, New Orleans, Chairman, Council on Drugs, American Medical Association, Member, Drug Research Board, National Academy of Sciences-National Research Council, Member, Revision Committee, and Chairman, Pediatric Panel. The Pharmacopeia of the United and Chairman, Pediatric Panel. The Pharmacopeia of the United
States; with 96 contributors. The C. V. Mosby Company, 11830 Westline Industrial Drive, St. Louis, Mo. (63141), 1971. 1222 pages, $\$ 34.50$.

This multiauthored reference work is published four years after the last edition. It contains fewer but larger pages, weighs more and is written by seven additional authors. The general organization is essentially that of the previous edition and much of the material and photographs are entirely unchanged. The book has 22 parts of which the first few comprise an overview of therapeutic problems in pediatrics. The remainder is divided into specialty sections of which the largest is devoted to infectious diseases.

The general discussions of therapeutic principles make excellent reading. Drug dosage schedules and the poisoning section can be useful as a reference handbook. Although the newborn chapter is a good, brief, general statement on the concepts of newborn care, it contains minor material already obsolete. This point more than any other illustrates the difficulty of trying to catch the rapidly changing field of therapy in a single work even if it is re-issued every four years.

Books of this sort are useful to the pediatrician and can often be quite valuable. Its general discussions are relevant for the student as an introduction and valuable as a refresher for the practitioner. I would recommend this book for departmental libraries, but would not for anyone holding the older edition. In these circumstances I would suggest selecting one of the other current therapy texts.

FrEDERIC KLEINBERG, MD 